\title{
Blood Donation Systems in Bangladesh: Problems and Remedy
}

\author{
Md Sahariar Hasan Jiisun ${ }^{1}$, Rasheda Akter Rupa ${ }^{2}$, Monzur Hussain Chowdhury ${ }^{3} \&$ Hasina Mushrofa $^{4} \& \mathrm{Md}$ \\ Rakibul Hoque ${ }^{5}$ \\ ${ }^{1}$ Founder, Bloodman, National Consultant, a2i, ICT Division, Bangladesh \\ ${ }^{2}$ Research Assistant, Bloodman, Bangladesh \\ ${ }^{3}$ Co-founder, Bloodman, Doctor, Bangladesh Cricket Board, Bangladesh \\ ${ }^{4}$ Mentor, Bloodman, Programme Head, BRAC Urban Development Programme, Bangladesh \\ ${ }^{5}$ Mentor, Bloodman, Bangladesh \\ Correspondence: Md Sahariar Hasan Jiisun, Founder, Bloodman, National Consultant, a2i, ICT Division, \\ Bangladesh. E-mail: jiisun.a2i.pmo@gmail.com
}

Received: March 20, 2019

Accepted: May 10, 2019

Online Published: July 15, 2019

doi:10.5539/ijbm.v14n8p145

URL: https://doi.org/10.5539/ijbm.v14n8p145

\begin{abstract}
Every year patients of various diseases need blood. Among them some need regular transfusion of blood. Hence, safe blood save life but unsafe one takes life. Ensuring regular flow of safe blood is a great challenge for the community in developing countries. Various public and private organizations are working for this purpose. Although the number of blood donor is increasing, there is still a huge gap in demand and supply of blood. A study has conducted to find out problems in getting blood donor in Bangladesh. Data have been collected from 430 respondents in different urban and rural areas of Bangladesh. Moreover, in depth interviews have conducted with hospital authority, blood donating organizations, public and private organizations and volunteers who work for various blood donating organizations. This study finds that patients need blood for delivery case $(76 \%)$, surgery (55\%), kidney diseases (33\%), thalassemia (37\%) and anemia (41\%). About 48\% blood seekers report that they require about 19-24 hours for managing each bag of blood. The seekers also report that they collect blood from relatives (77\%), blood donating organizations (33\%) and blood bank (26\%). About 26\% donors report that they have to pass more than $6 \mathrm{~km}$ for blood donation. They also spend money more than 100 taka $(12 \%)$ for this purpose. Before and during blood donation, donors face several problems such as transportation problem (38\%), coping with emergency case (32\%), unskilled staff $(29 \%)$, health related problem $(15 \%)$ and lengthy cross checking process $(35 \%)$. There are a number of people want to donate blood willingly. However, they can't donate due to lack of available communication with blood seekers. Maintaining database of donors, training staffs and using technologies and machines for blood donation process can solve problems in blood donation.
\end{abstract}

Keywords: blood, donor, blood donation and blood seekers

\section{Introduction and Background}

Every year a number of people die due to lack of safe blood. Patients suffering from various kinds of diseases and accidents need blood. Especially the patients of thalassemia, sickle cell disease and cancer need regular blood transfusion. There is a time laps within which collected or stored bloods need to be used. Otherwise, collected or stored blood can't be used. In this case, it is necessary to have a regular flow of blood in blood banks or blood donating organizations to meet the regular demands. Besides, people need blood for pregnant mothers in case of delivery and for various surgical processes. Hence, blood is considered as the best gift given by a people to another. Safe blood gives life to people (WHO, 2018).

In 1950, Bangladesh Blood transfusion service was launched at Dhaka medical college hospital (Islam, 2009). Then with the passage of time many more blood transfusion centers have been established to ensure availability of blood in need of time. But in that time the blood centers' main responsibility was only to do blood grouping and cross matching. There was no initiative to supply safe blood to the patients. No blood center either public or private screened blood as it was optional in those days. As a result, people became concerned with various diseases like HIV, Viral Hepatitis and many other transfusion transmissible infections spread through transfusion 
of blood from one individual to another.

In Bangladesh, 97 Blood Transfusion Service centers at various districts started a program to screen blood with the support of UNDP in 2000. Screening tests involved HBsAg test, VDRL (Venereal Disease Research Laboratory) test, Malarial Parasite test, Anti-HCV test, Anti-HIV test (Islam, 2009). It has been found that only $26 \%$ blood donors were voluntary donors. About $47 \%$ blood was collected from professional donors while $27 \%$ blood was collected from family replacement donors (Islam, 2009).

According to a study conducted by Islam (2009), 3,23,642 units of blood were collected by 97 Blood Transfusion Service (BTS) centers in Bangladesh from January 2001 to May 2003. Among them, there were 6143 units of TTI-positive blood and 4,467 units were HBsAg-positive units. Moreover, Hepatitis C was positive in 466 units, syphilis was positive in 1,120 units, malaria was positive in 83 units.

Among total demand of blood only $25 \%$ of the units can be managed from non-commercial voluntary blood donation programs while about $50 \%-55 \%$ units are managed from one time donors or replacement donors who donate blood just for having no alternatives in emergency. The rest of the units are provided by professional donors which is quite risky initiative. Although in Bangladesh blood donation service was started in 1950, voluntary blood donation was initiated in 1978 by Sandhani camp in Dhaka medical college hospital (bdnews24.com, n.d.).

There are three major sources of blood -paid or professional donors, patients' relatives or replacement donors and volunteer donors. Youth is the main source of voluntary blood donation. To ensure the availability of safe blood for the patients, young can be encouraged.

According to a report published by World Health Organization (2018) there were an approximate need of 800000 units of blood. But on 600000 units were collected from the donors by both public and private transfusion centers situated in all over the country. Among 600000 units of collected blood only $31 \%$ came from voluntary blood donors (World Health Organization, 2018). This scenario reveals that there is still a huge gap in demand and supply of blood. To address the above mentioned problems associated with blood donation in Bangladesh, this study has been conducted.

\section{Objectives}

The main objective of the research is to find out problems getting blood donor in Bangladesh. Based on the major objective a number of specific objectives have been developed. Which are as follows:

- Finding out the challenges and difficulties of getting donor and blood

- $\quad$ Finding solutions to meet these challenges

- Using TCV (Time, Cost and Visit) model in finding and getting blood

- Finding ways to encourage people to donate blood

\section{Literature Review}

Tagny et al. (2008) has made a conclusion on the status of availability of safe blood and difficulties of getting safe blood in Africa. It has been found that lacking in development and adoption of national policy in blood transfusion leads to difficulty in voluntary blood donation in Africa. They also suggested that funding and proper monitoring for the governance of blood transfusion services could assure blood availability and safety.

According to World Health Organization (2017) availability of safe and sufficient blood and blood products and safe transfusion system are the indicators of a good health care system. It has been found that developing and low resource countries face more problems in supplying safe and sufficient blood and blood products for their citizens. World Health Organization (2017) reveals that 180 countries made 112.5 million blood donations in 2013 including both paid and voluntary. Among donors overall $40 \%$ were between 25 years to 44 years and $70 \%$ donors were male (Regional Status Report on Blood Safety and Availability, 2016).

World Health Organization (2017) also stated that overall 122 countries had a national policy while 127 countries formed a unit affiliated with ministry of health to govern the collection and transfusion of blood and blood products by 2013. It concludes that voluntary blood donation is the key component to ensure sufficient and safe blood and blood products ("Blood safety and availability," n.d.).

Sun, Lu, \& Jin (2016) collected data from a Chinese blood bank on 447,357 blood donors and suggested two methods to fulfill shortages of blood. The first method is to motivate donors to donate blood voluntarily using mobile messages and the second method is to encourage relatives to donate blood while a family replacement program takes place. Both methods resulted in an increase in voluntary blood donation in China. 
Knowledge, attitudes and practices surveys have been conducted in diffident countries to determine the motivations and attitudes of blood donors. A sample of 17 developing countries (characterized by International Monetary Fund) have been selected to determine knowledge, attitudes and practices of blood donation. Lack of proper information about blood, donors' phobia in donating blood, lack of positive attitudes about blood donation, existence of the trend of selling blood and blood products were the major findings of the studies (Lownik, Riley, Konstenius, Riley, \& McCullough, 2012).

A study has been conducted on 936 adults in Northern Nigeria to assess the knowledge and practices of blood donation. It has been found that people awareness regarding voluntary blood donation was not up to the mark. Most deter to donate blood due to HIV screening. Public awareness program and motivational program including free medical services can be adopted to raise awareness regarding voluntary blood donation (Salaudeen et al., 2011).

Several misconceptions exist among Saudi Arabia people regarding blood donation. Alam \& Masalmeh (2004)interviewed 500 males in Saudi Arabia to assess their knowledge, attitudes and practices of blood donation. Among them only 58.2\% (291 people) were donors. Among 291 donors only $36.1 \%$ donated blood voluntarily. $94.2 \%$ (471 people) answered that a person with 45 years old couldn't donate blood. $51 \%$ non-donors relied that a person could donate blood once a year while $42.6 \%$ non-donors revealed that they were not asked for blood donation by any blood seeker.

A study has been conducted in China on 1280 people involving blood donor group, non-donor group, students and workers from 8 different cities to assess the knowledge, attitudes and practices of blood donation. Two kinds of factors have been identified by this study- motivating factors and inhibiting factors. Motivating factors for blood donation are social pressure and being able to know screening results while getting affected by infection and adverse health consequences are considered as inhibiting factors of blood donation (Zaller et al., 2005).

In developed countries blood supply increases but this creates new challenges for those countries. Challenges for developed countries are to adopt proper care in collecting blood from donors, to recruit and retain future blood donors, to adopt integrated approaches to manage blood so that blood wastage can be reduced (Williamson \& Devine, 2013).

According to Klein, Spahn, \& Carson (2007) about 75 million units of blood especially red blood cells are collected over the globe annually. Among them 13 million units of blood remains untested for HIV or hepatitis viruses. Due to lack of proper testing and screening infection risks is increasing in developing countries.

Busch, Kleinman, \& Nemo (2003) states that today blood borne infections has been reduced significantly in US in blood transfusion. They emphasize on the characteristics of transfusion transmitted pathogens, development in measuring blood donor and blood seeker infection rates, early viremia dynamics characterization, adoption of more and more criteria in selection of blood donor and development in laboratory screening as factors of reduction in blood borne infections.

According a study of knowledge and attitude practices conducted by Waheed, Zaheer, \& Knowledge (2015) voluntary blood donation rate in Pakistan very low. Only $10 \%$ of blood comes from voluntary sources while rest $90 \%$ of blood comes from relatives, friends and paid donors. Blood seekers express concerns regarding blood safety and blood screening.

A study on 200 students of Dhaka university in Bangladesh revealed that voluntary blood donation tendency mostly exists among students. Physical harm and fear to donate blood are considered as the most inhibiting factors for blood donation (Hosain, Anisuzzaman, \& Begum, 1997)

In Bangladesh most maternal death occurs due to lack of blood in emergency. Blood Information and Management Application (BIMA) is an online service for blood seekers to get blood in emergency through blood brokers. This service raises an issue of safety of provided blood which is unknown to both blood seekers and blood providers (Akhter et al., 2016).

On $14^{\text {th }}$ June the whole world celebrates World blood donor day. Through this celebration voluntary donors are encouraged to donate blood to ensure availability of safe and quality blood. Availability of safe and quality blood and blood products represents the effectiveness of health system of a country. Celebration of world blood donor day creates awareness among people. (World blood donor day 2018, n.d.)

A report published by Dhaka Tribune (January, 2018) mentions that facebook can be used to find donors easily and safely. To effectively work with facebook feature non-profit organizations, health industry experts and potential donors must cooperate. This feature of facebook creates connection between blood seekers and blood donors. 


\section{Methodology}

Data has been collected from the respondents using questionnaires. Different sets of questionnaires have been used for different groups of people such as blood donors, blood seekers, hospital authorities, blood banks, blood donating organizations, private and public organizations and volunteers associated with this study. Each questionnaire includes both close ended and open ended questions. Blood donors, relatives of patients and volunteers are considered as the study population for this study. In depth interview has been conducted with Hospital authority, Blood bank authority, Corporate and Government organizations, and Blood Donating organizations. Data has been collected from 8 districts of 4 divisions from both urban and rural areas which have been selected simple random sampling.

A sample size of 430 respondents has been used. Among them 165 respondents were from rural areas and rest 265 were from urban areas. Collected data has been edited properly and then information has been classified on the basis of their characteristics. Data has been analyzed with the help of SPSS software.

Table 1. Sampling method and sample size

\begin{tabular}{|c|c|c|c|}
\hline \multicolumn{2}{|c|}{ Methods } & \multirow{2}{*}{$\begin{array}{l}\text { Target group } \\
\text { Blood donors }\end{array}$} & \multirow{2}{*}{$\begin{array}{l}\text { Number } \\
200\end{array}$} \\
\hline 1 & Sample survey & & \\
\hline & & Blood seekers & 200 \\
\hline & & Volunteers & 30 \\
\hline \multirow[t]{4}{*}{2} & In depth Interview & Hospital authority & 5 \\
\hline & & Blood bank & 5 \\
\hline & & Blood donating organization & 5 \\
\hline & & Corporate and government organization & 5 \\
\hline
\end{tabular}

\section{Findings of the Study}

\subsection{Findings from Blood Seekers and Blood Donors}

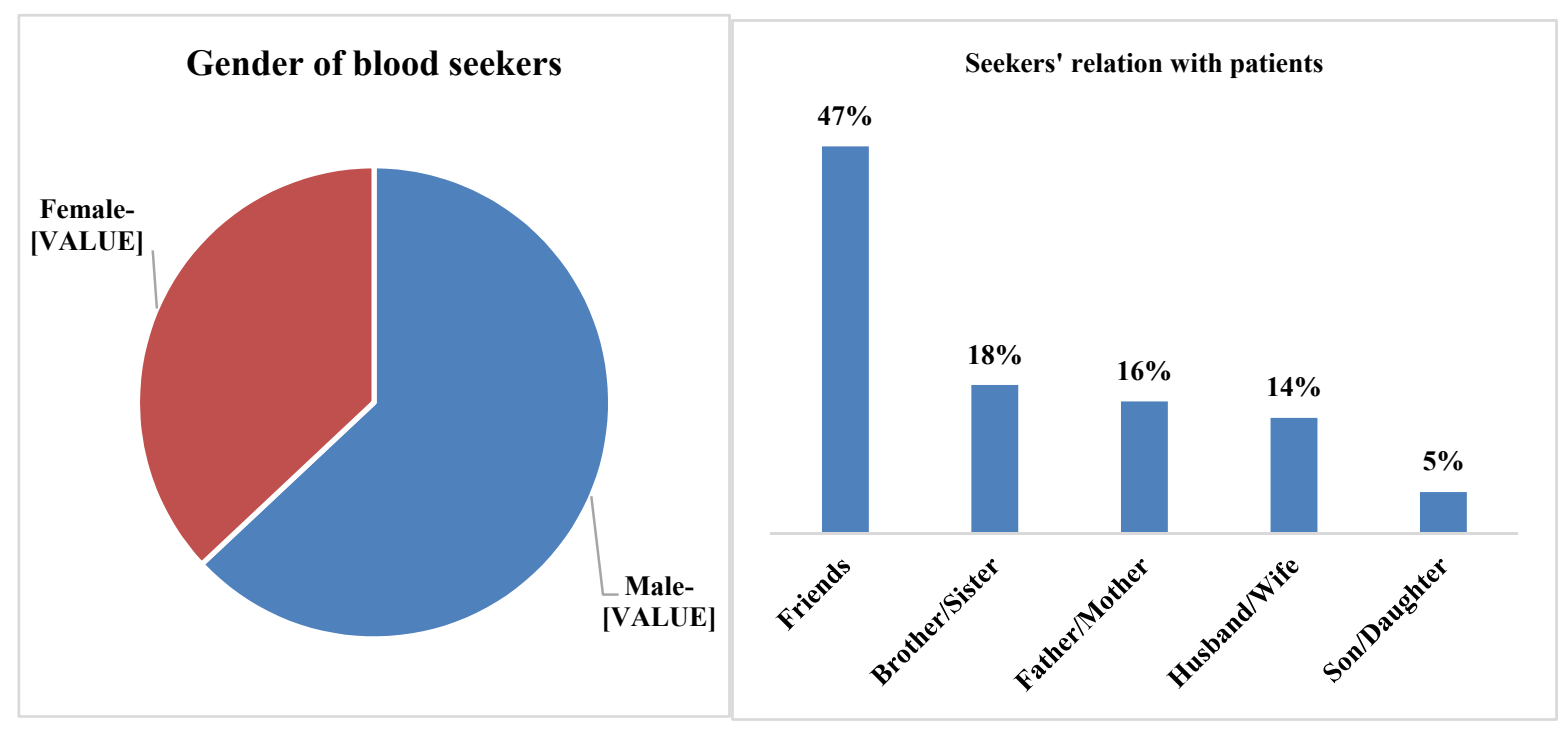

Figure 1. Gender of blood seekers (a) and seekers' relation with patients (b)

Figure 1 (a) represents the gender of the blood seekers. It has been found that there were $63 \%$ male blood seekers and $37 \%$ female blood seekers who looked for blood their relatives and friends. 
Figure 1 (b) represents blood seekers' relation with the patients for whom blood was searched and collected. It has been found that about $47 \%$ respondents searched for blood for their friends. About $18 \%$ respondents have searched for blood for their brothers or sisters while $16 \%$ blood seekers searched for blood for their father and mother.

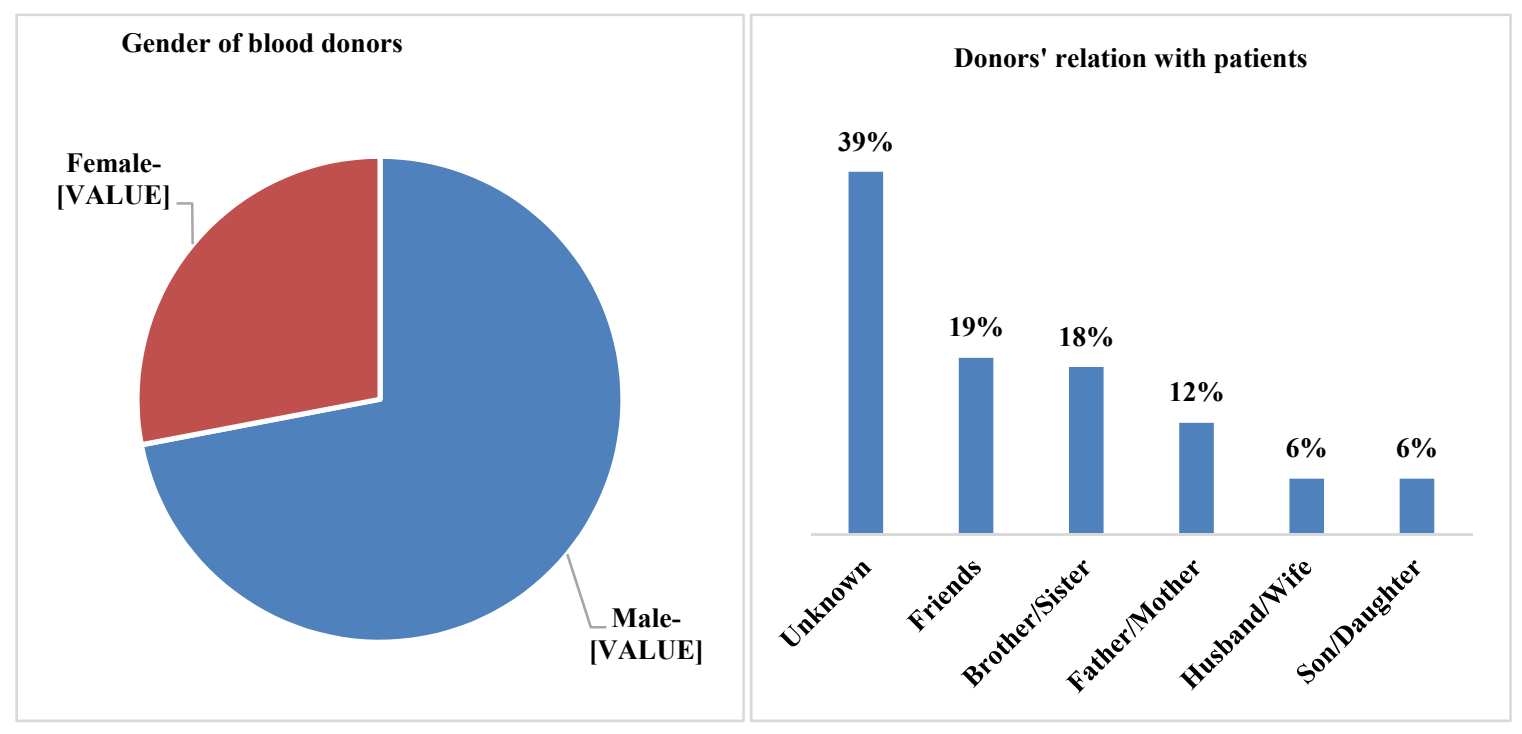

Figure 2. Gender of blood donors (a) and donors' relation with patients (b)

Figure 3: Gender of blood donors (a) and donors' relation with patients (b)

Figure-2 (a) represents the gender of the blood donors. There were $72 \%$ male donors and $28 \%$ female donors.

Figure-2 (b) represents blood seekers' relation with the patients. It has been found that about 39\% respondents donated blood to unknown patients. About 19\% donors have donated blood to their friends. About 18\% respondents have donated blood to their brothers or sisters

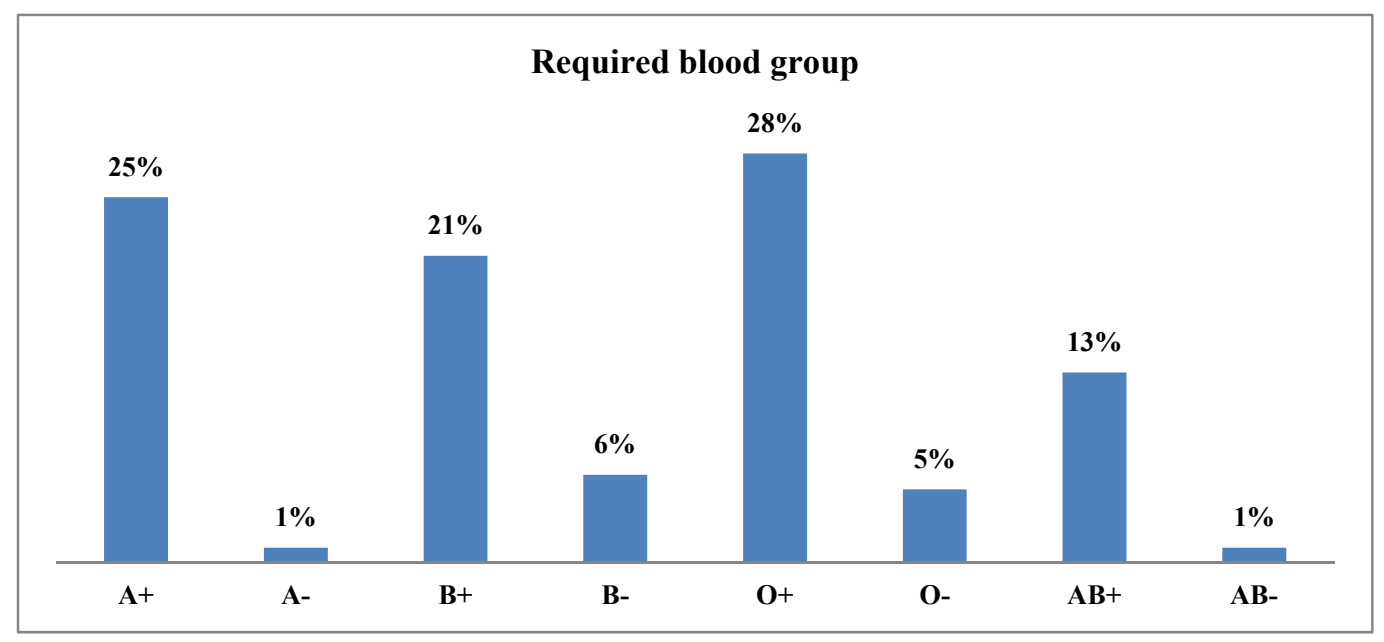

Figure 4. Required blood group

Figure 3 represents the percentage of blood searched and collected for each group. It has been found that majority $(28 \%)$ of the respondent's searched for and collected O+ blood. About $25 \%$ respondents have searched for and collected A+ blood. About 21\% of the respondents have searched for and collected B+ while $13 \%$ respondents have searched for and collected $\mathrm{AB}+$ blood. 


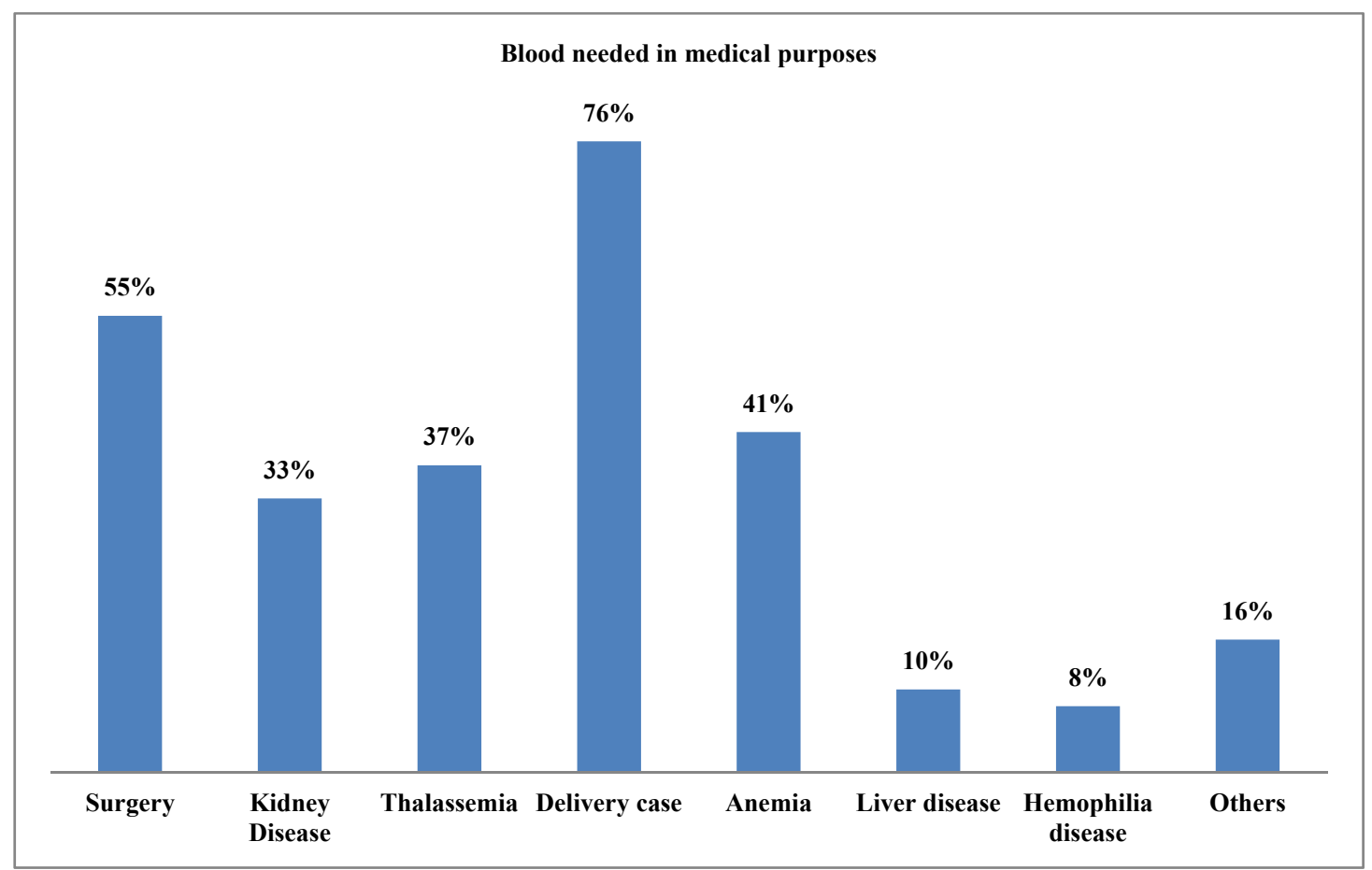

Figure 5. Blood needed in different medical purposes

Note. Multiple response.

Figure-4 shows the reasons or cases of blood donation. It has been found that blood is needed in most of the delivery cases $(76 \%)$. About $55 \%$ respondents have mentioned that they donated blood to surgery patients. Only $4 \%$ respondents have donated blood to hemolytic patients. About $41 \%$ donors have mentioned that anemia was the reasons of blood need.

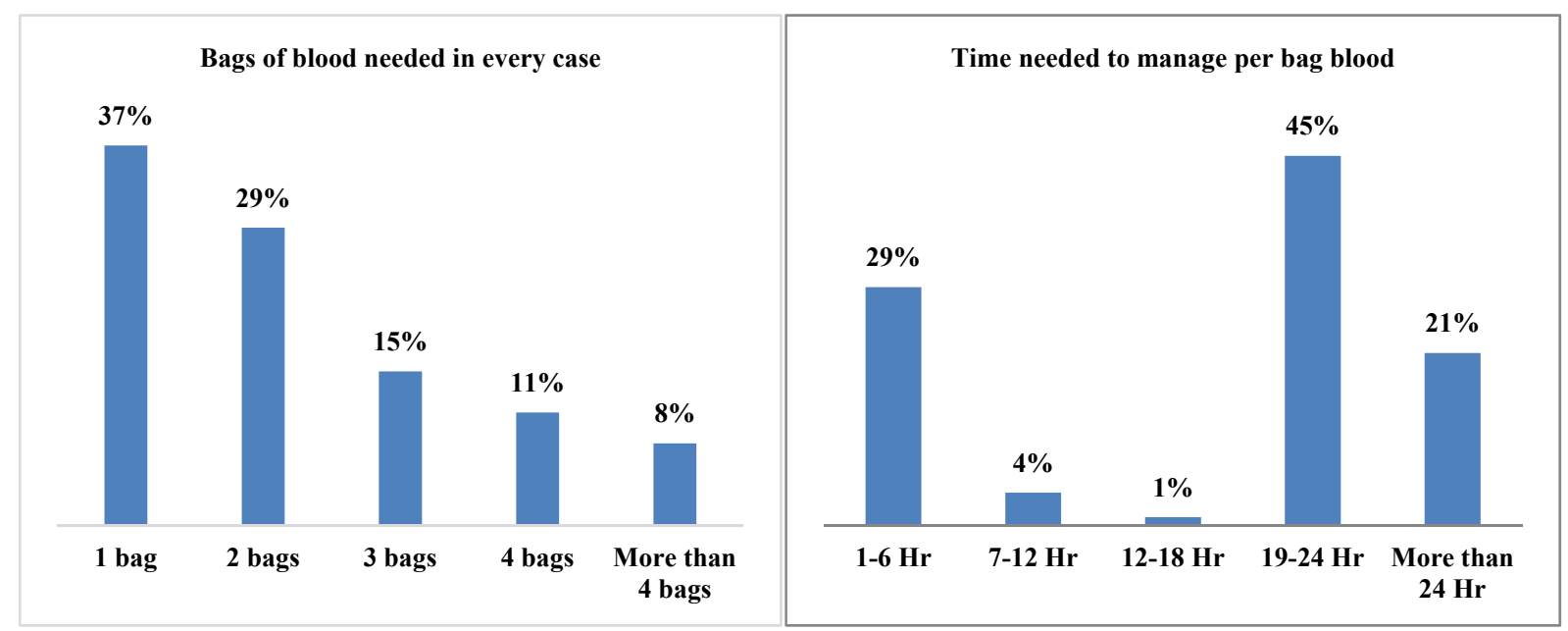

Figure 5. Bags of blood needed in every case (a) and time needed to manage per bag blood (b)

From figure 5 (a) it has been found that majority (37\%) respondents needed one bag blood. On the other hand, only $8 \%$ respondents have opined that they needed more than four bags blood. About $29 \%$ respondents have mentioned that they needed two bags of blood.

Figure 5 (b) represents the time needed by the blood seekers to collect a bag of blood. Majority (45\%) of the respondents have mentioned that they required 19-24 hours to collect each bag of blood. Only $1 \%$ has reported that they needed 12-18 hours to collect per bag blood. 

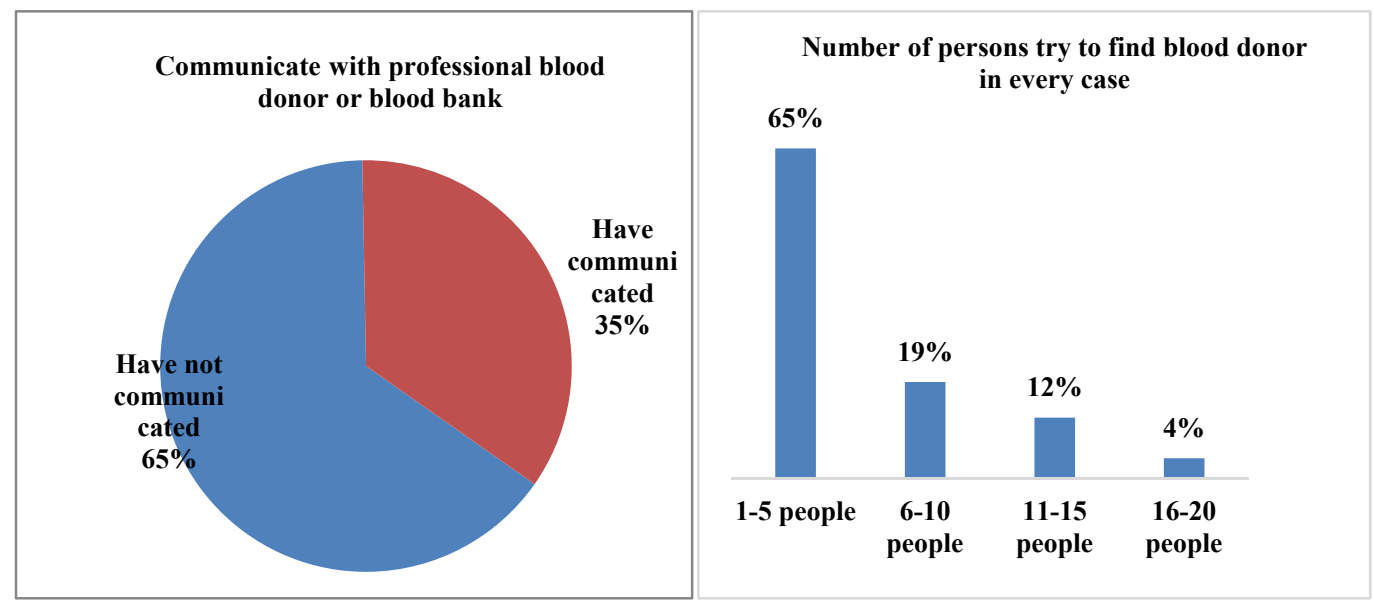

Figure 6. Manage blood from professional blood donor or blood bank (a) and Number of persons try to manage blood donor in every case (b)

Figure 6 (a) represents the number of blood seekers who have to communicate with professional blood donor or blood bank to manage blood. About 35\% respondents have communicated with professional blood donors or blood banks to manage blood for their patients. About $65 \%$ respondents have not communicated with professional blood donors or blood bank.

Figure 6 (b) represents the number of people one has needed to contact to manage blood. About $65 \%$ respondents have mentioned that they made contact with 1-5 people to manage each bag of blood while only $4 \%$ have reported that they needed help from 16-20 people. About 19\% respondents have opined that they needed help from 6-10 people.

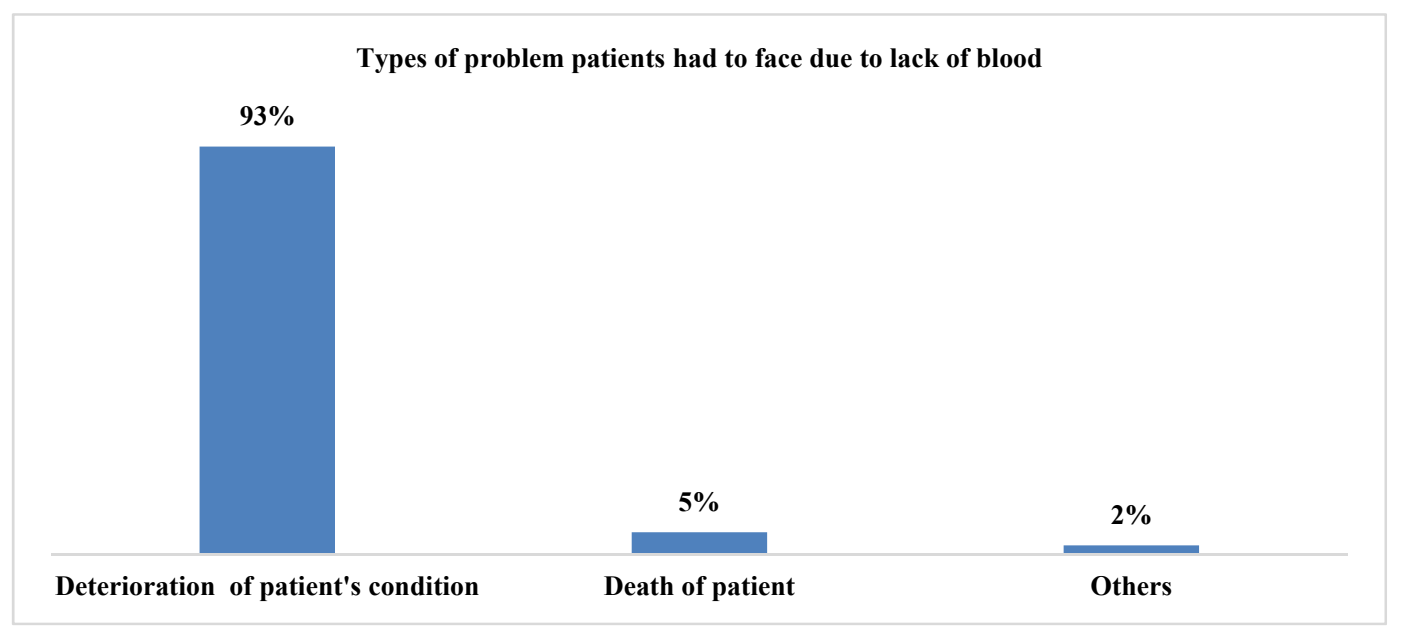

Figure 7. Types of problem patients had to face due to lack of blood

Figure-7 represents the types of problems faced by patients due to not having blood in time. Majority (93\%) have reported that patients' condition became worse due to not having blood in time. About 5\% respondents have reported that their patients died due to lack of negative group blood on time. Usually surgery patients and delivery patients need blood for immediate operations. Failure to supply blood in time results in death. Only $2 \%$ have reported other problems such as complex treatment. 


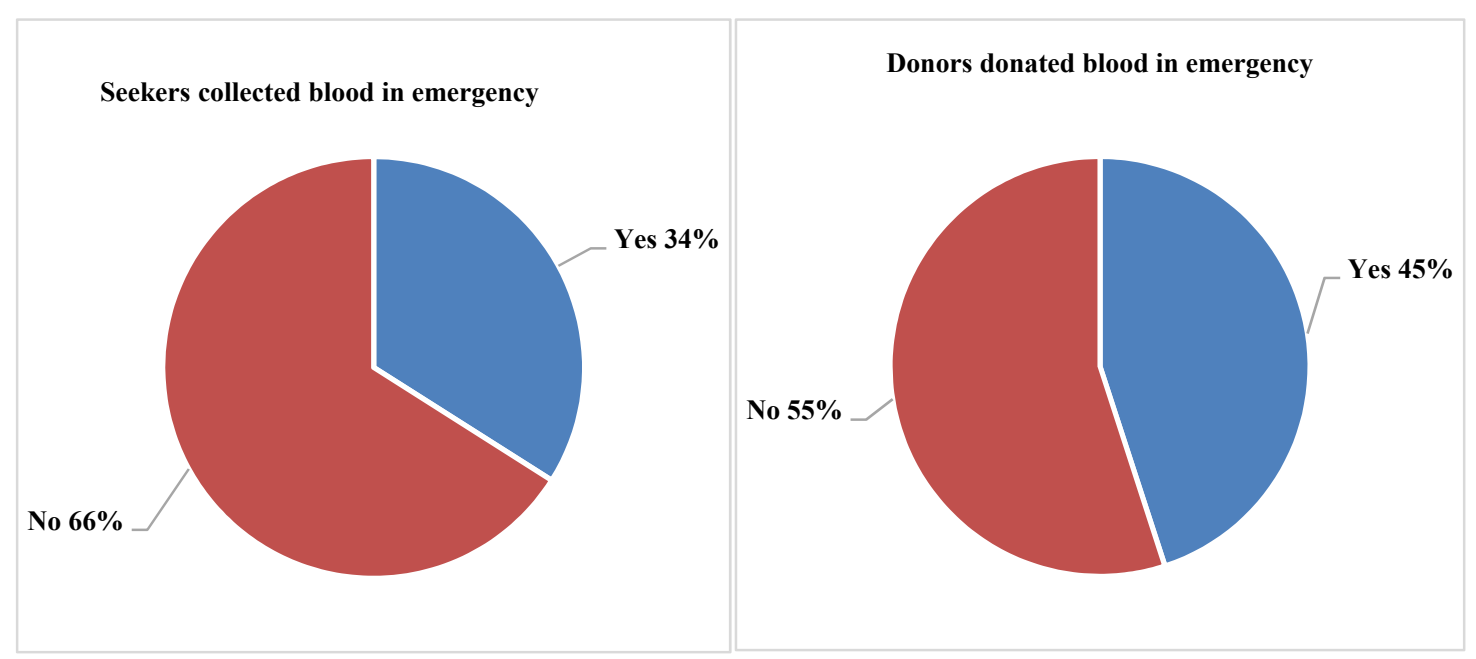

Figure 8. Seekers collected blood in emergency (a) and donors donated blood in emergency (b)

Figure 8 (a) represents number of patients who have needed blood for emergency case. About 34\% respondents have opined that they needed blood for emergency case such as delivery or surgery while the rest of the respondents did not needed blood for emergency case.

Figure 8 (b) represents donors who donated blood in emergency case. It has been found that about $45 \%$ donated blood in emergency case. Rest of the respondents has opined that they did not donated blood in emergency case.

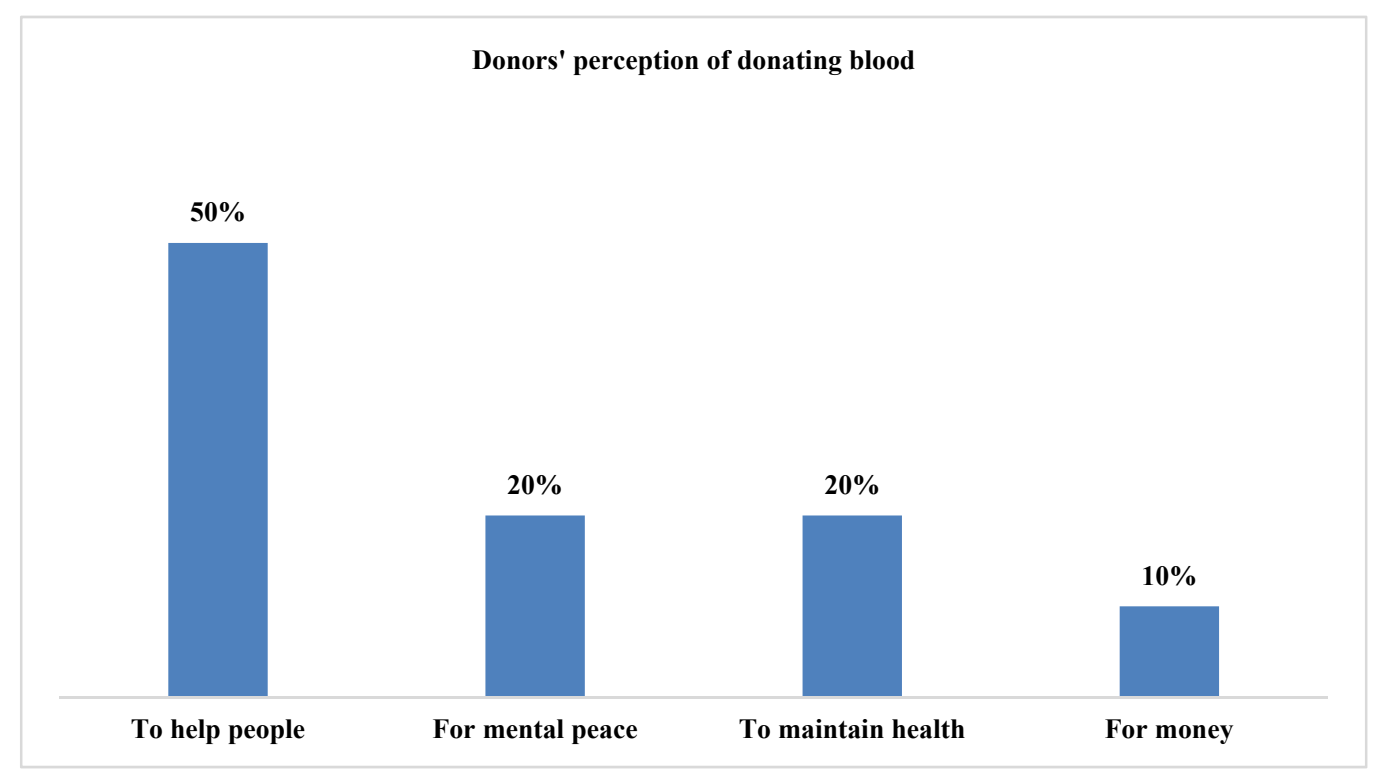

Figure 9. Donors' perception of donating blood

Figure 9 explains why donors donate blood to others. It has been found that about $50 \%$ donors donated blood to help people. About $29 \%$ respondents have revealed that they donated blood for their mental peace. Only $10 \%$ respondents have expressed that they donated blood for money. Although seekers collected blood from professional donors, donors donated blood voluntarily too. 


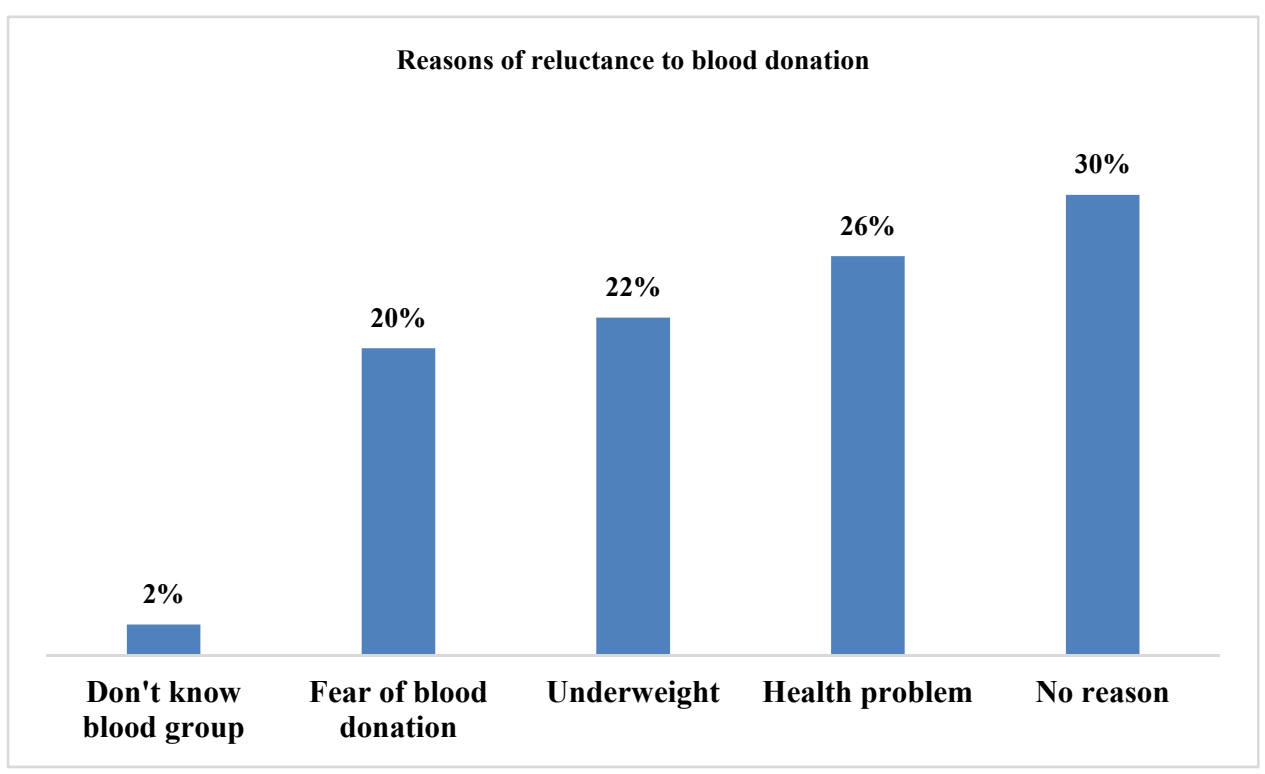

Figure 10. Reasons of reluctance to blood donation

Figure 10 describes the reasons why do people oppose to donate blood. More than 150 million people live in Bangladesh but still Bangladesh face crisis of blood. Majority, 30\% of the respondents, have opined that they had no reason against not donating blood. About 26\% respondents had health problems while $22 \%$ respondents were under weight to donate blood. Only $2 \%$ respondents did not donate blood because they were unaware of their blood group. Other $20 \%$ have revealed that they were afraid of donating blood.

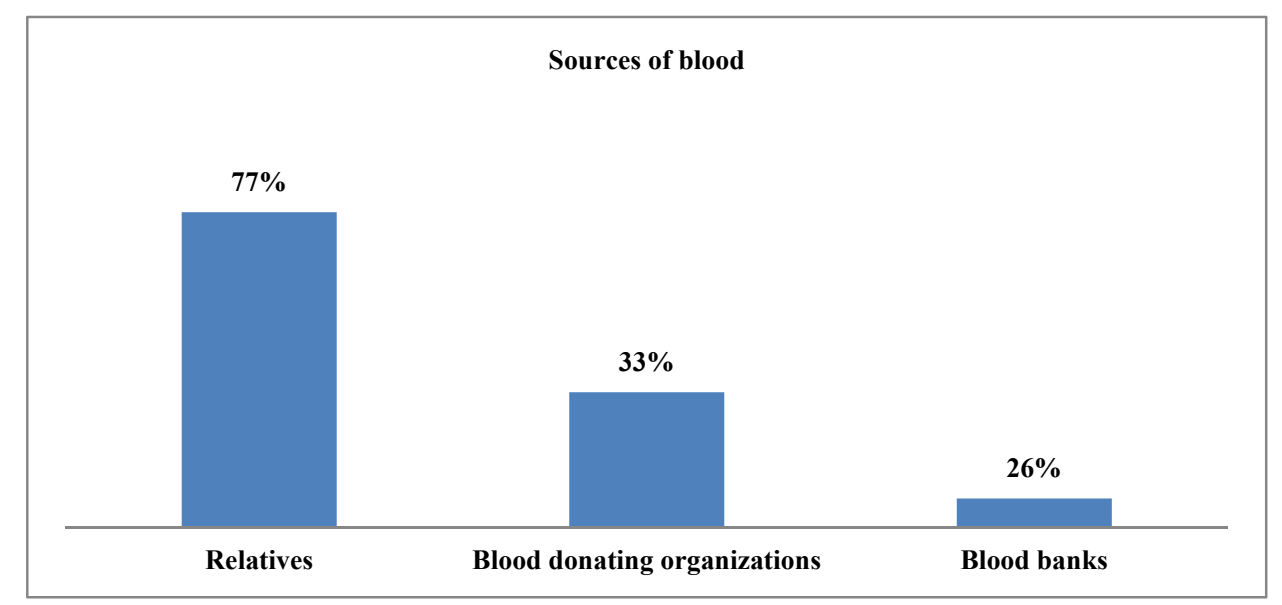

Figure 11. Sources of blood

Note. Multiple responses.

Figure 11 represents the sources from which blood seekers collect blood for their nearest and dearest ones. It has been found that majority (77\%) collected blood from their relatives. About 33\% respondents have opined that they collected blood from various blood donating organizations such as Badhon, Sandhani, Bloodman and on. 


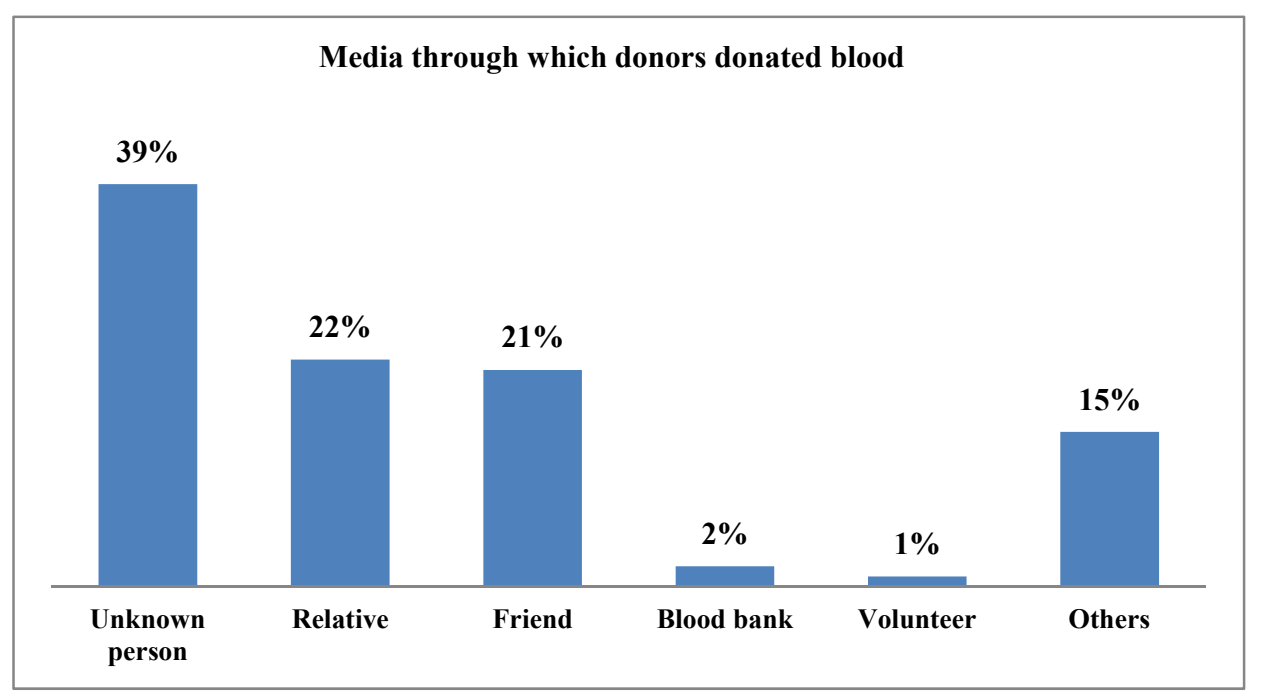

Figure 12. Media through which donors donated blood

Figure 12 shows the media through which donors donated blood. Most of the respondents (39\%) have mentioned that they donated blood via unknown persons. It has often happened that donors got information of blood need from their friends or relatives and donated blood for unknown persons. About $22 \%$ respondents have donated blood via their relatives. Only $1 \%$ has donated blood via volunteers.

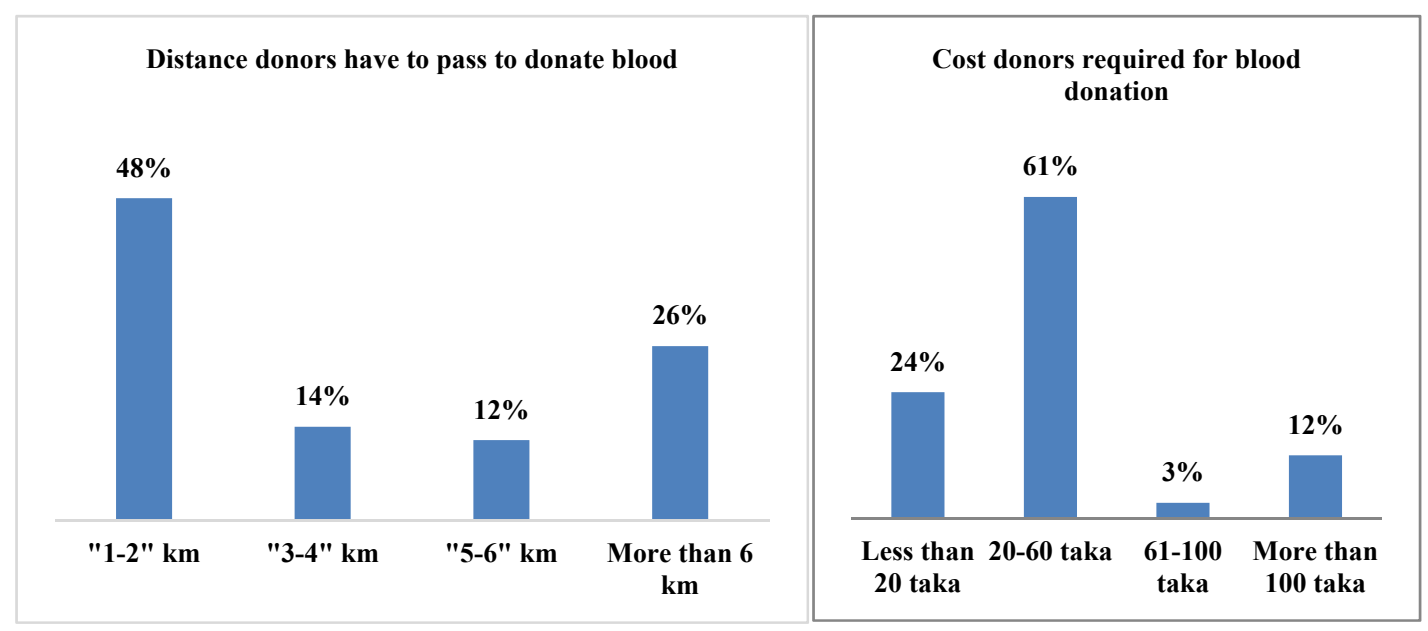

Figure 13. Distance donors have to pass to donate blood (a) and cost donors required for blood donation (b)

Figure 13 (a) describes how much distance donors have to pass to donate blood. It has been found that about $48 \%$ donors had to pass $1-2 \mathrm{~km}$. About $26 \%$ respondents have opined that they had to go for more than $6 \mathrm{~km}$ to donate blood. Due to long distance it seems costly to donate blood. It is also time consuming. For this reasons donors become discouraged to donate blood.

Figure 13 (b) represents how much money donors had to spend for last blood donation. It has been found that majority (61\%) respondents spent 20-60 taka for last blood donation. About $24 \%$ have told that they spent less than 20 taka while $12 \%$ of the respondents have expressed that they needed to spend more than 100 taka for most recent blood donation. 


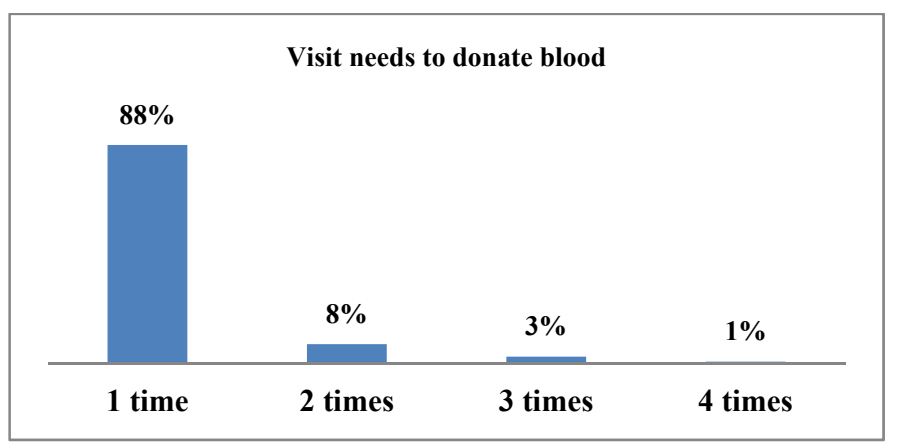

Figure 14. Visit needs to donate blood

Figure 14 reveals number of visits needed by donors to donate blood each time. It has been found that $88 \%$ respondents donated blood by one visit. About $1 \%$ respondents have told that they needed 4 visits to donate blood each time. About $8 \%$ donors have opined that they needed 2 visits for blood donation.

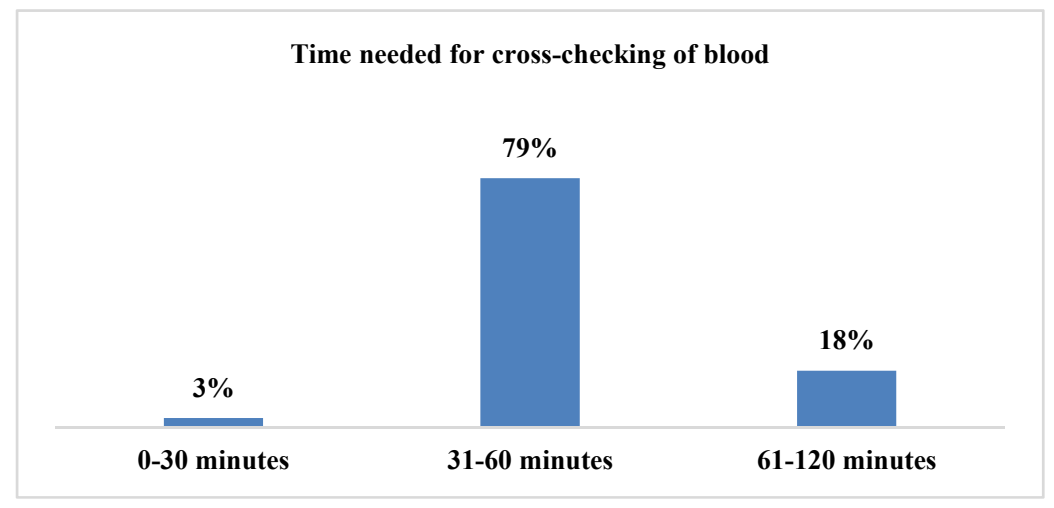

Figure 15. Time needed for cross checking of blood

Figure 15 shows time needed for cross checking during blood donation. It has been found that it took 30-60 minutes according to $79 \%$ donors. Only $3 \%$ respondents have told that it took $0-29$ minutes. About $18 \%$ respondents have mentioned that it took 60-120 minutes for cross checking. They have reported that most often they had to wait due to having insufficient tools for cross checking or due to redundancy of efforts by unskilled workers.

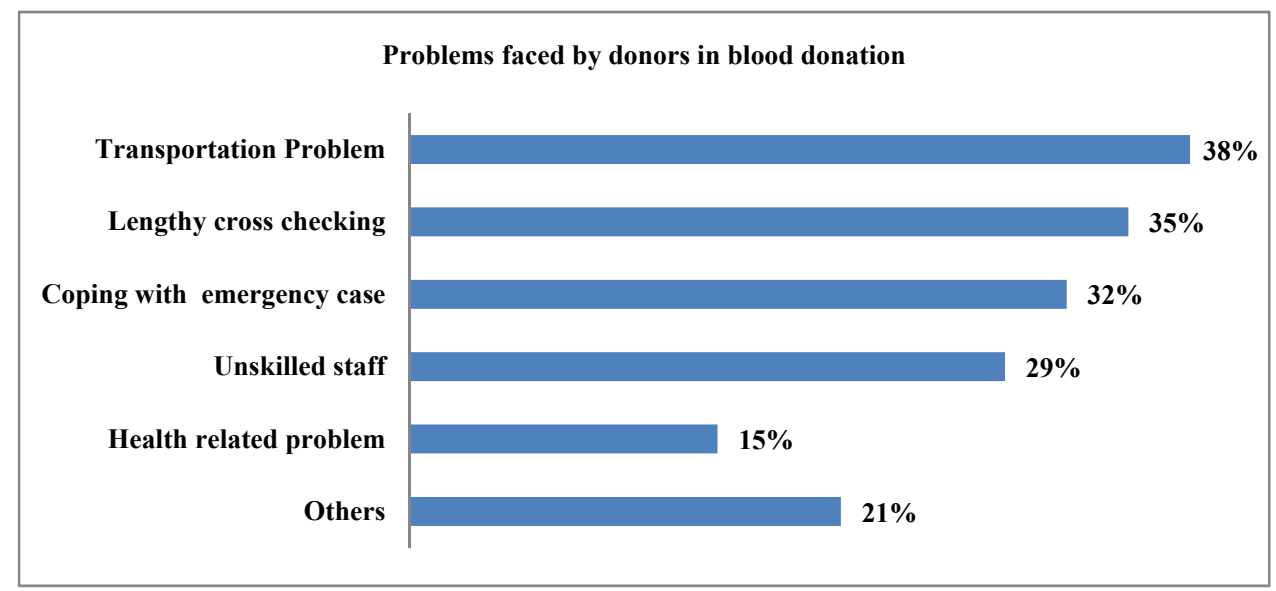

Figure 16. Problems faced by donors in blood donation

Note. Multiple responses. 
Figure 16 represents the problems faced by blood donors. It has been found that about $38 \%$ respondents faced transportation problem like unavailability of transportation or traffic jam. About $35 \%$ have opined that cross checking needed more time. About 29\% respondents have mentioned that workers associated with blood transfusion process were unskilled. Another $15 \%$ donors have faced health related problems.

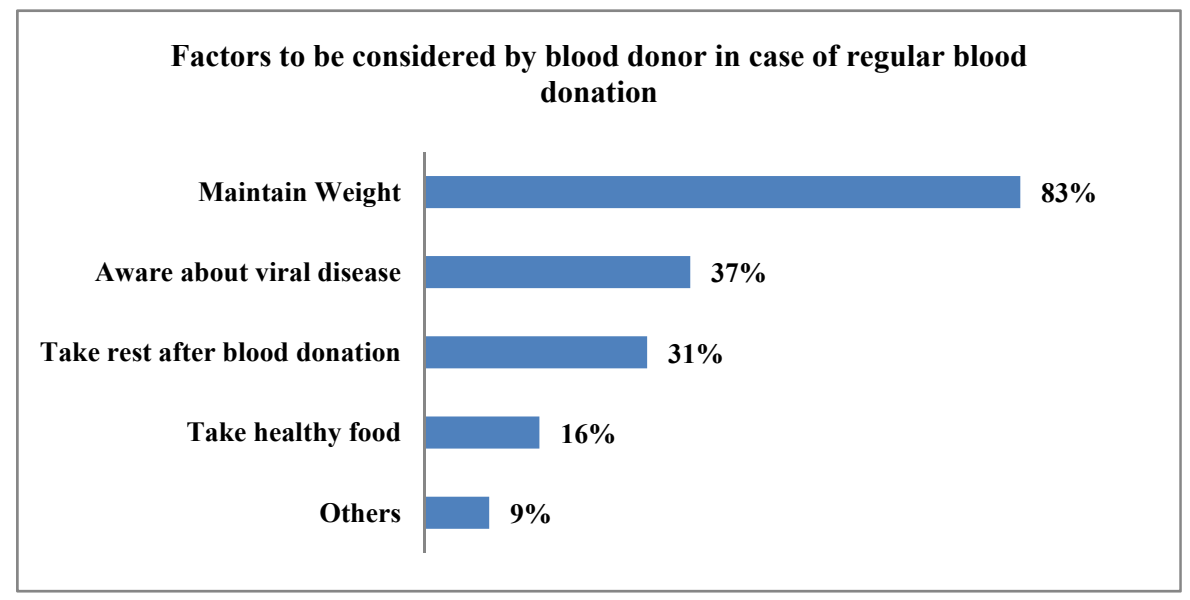

Figure 17. Factors to be considered by blood donor in case of regular blood donation

Note. Multiple responses.

Figure 17 shows the factors that blood donors should consider in case of regular blood donation. About $83 \%$ have mentioned that maintaining weight was the most important factor for regular blood donation. About $37 \%$ respondents have suggested that donors should be aware of viral diseases. Taking sufficient rest after blood donation has been suggested by about $31 \%$ respondents.

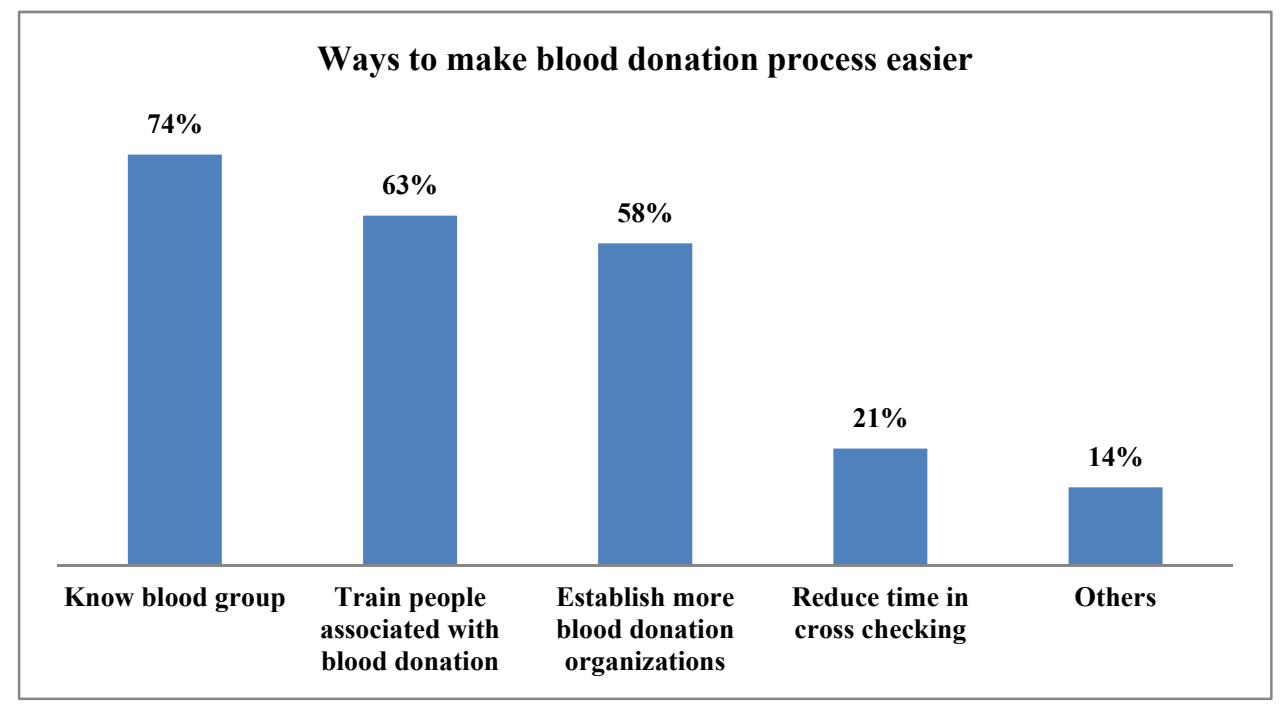

Figure 18. Ways to make blood donation process easier

Note. Multiple responses.

Figure 18 represents the ways of making blood donation process easier. Most of the respondents (74\%) have revealed that knowing blood group could make blood donation process easier. Another $63 \%$ respondents have suggested that training people associated with blood donation process made blood donation process easier. Establishment of more blood donation organizations has been reported by $58 \%$ respondents. According to $21 \%$ respondents, reduction of time in cross checking process could make blood donation process easier. 
Bangladesh has 166.37 million people (Bangladesh Population Demographics, Maps, Graphs, 2018). According to Bangladesh Telecommunication Regulatory Commission (July, 2018) 88.687 million people of Bangladesh subscribes internet using various operators such as mobile phones (82.912), WiMAX (0.084) and ISP+PSTN (5.691). It reveals that only 53.307\% people use internet. 28 million people use facebook in Bangladesh (Asia Internet Usage Stats Facebook and 2018 Population Statistics, n.d.). 1.37 million Facebook users are of 18-24 years old (Business Habit, 2017).

\subsection{Findings from Doctors and Blood Donating Organizations, Public and Private Organizations and Volunteers}

One respondent has said that the monthly demand of blood in $\mathrm{DMCH}$ is about 4500-5000 bags of blood. Among them about $30 \%$ is collected from Badhon (a voluntary blood donation organization) and $40 \%$ from relatives of blood seekers. Hospital authority does not have previously collected blood in their blood bank. Donors did not come to donate blood willingly. Seekers managed donors by using their personal networks. Most of them were not aware of their blood group. For this she has suggested that awareness development program should be broadcast in electronic media. Printing media can also play a significant role. She has suggested donors should be aware of viral diseases and weight. Usually cross checking took a long time from donors which discouraged them. Use of modern technologies and machines in this regard can improve performance.

A group of volunteers have been asked of various aspects of blood donation. Valuable information has been solicited from them. They have revealed that lack of awareness of the benefits of blood donation and phobia among the donors was the main reasons not donating blood. They have also suggested that creating database of donors and making it available to hospital and thereby to the seekers could be good initiatives to create a good communication between blood seekers and blood donors. Seminar, symposium, motivational programs, social media and printing media can motivate people to donate blood and also to reduce phobia of donating blood. Free blood group testing programs can also play a major role in this regard.

By interviewing managers and staffs of various public and private organizations, it has been found that they maintain a database of blood group of their employees to supply blood donors in case of emergency of the staffs. They have also mentioned that sharing this information with blood bank could lead to a good connection with blood donors and seekers but most of the organization refuged to share such information.

\section{Discussion}

From the study it has been found that most of the people are unaware of their blood group. They even fear of donating blood. Although physicians suggest that a person can donate blood after every four months, people are reluctant to donate blood. Through seminar, campaigns, symposium, program in electronic media and printing media people can be made aware of benefits of donating blood regularly.

An effective association of educational organizations and public and private commercial organization with transfusion medicine and other units where people go for searching blood can create a bridge between seekers and donors. In this regard, maintaining a central database of people involved in those organizations can reduce effort of getting donors and managing blood in case of emergency. Although a part of our population are willing to donate blood, they can't donate blood due to lack of communication with blood seekers.

Most often donors are not willing to donate blood due to previous bad experience they had during blood donation. Often donors have to wait for a long time in queue in before transfusion due to lack of facilities. Using modern technologies and machines can reduce time in cross matching and associated tests as well. Moreover, training facilities can improve efficiency of the staffs.

Based on the study the following steps can be recommended to improve the current blood donation scenario of Bangladesh:

1. Encouraging people to donate blood via seminar, symposium, and motivational program broadcast on electronic media and campaign. This initiative can help to remove the fear of donating blood among donors.

2. Free blood group checking campaign should be conducted so that people become aware of their blood group.

3. Database making all over Bangladesh to contact nearest people to donate blood and create a connection between donors and seekers.

4. Training the people associated with transfusion can improve performance in blood donation process. 
5. Blood bank, hospitals and associated organizations should use modern technologies and machines for testing, transfusing and preserving blood.

\section{Limitations of the Study}

This study has some limitations such as sample size, time, budget etc. In this study only a few districts have been considered where Bangladesh has 65 districts. Hence, it is quite certain to have some deficiency in collecting data due to time and budget constraints and selective area. Moreover, ignorance of respondents regarding the solicited data can be considered another limitation.

\section{Conclusion}

Due to lack of voluntary blood donation in Bangladesh, blood seekers have to manage blood from professional blood donors. This source most often fails to provide fresh blood and costly too. On the other hand, these blood units carry toxic elements which is dangerous for patients. As a result, a number of patients die every year. Managing blood is quite costly and difficult for blood seekers although a great portion of donors donate blood voluntarily. Lack of information and communication is the main cause of difficulty and unavailability of blood in our country. Besides, ignorant of benefits of blood donation is another cause.

Encouraging people through various programs and campaigns can make it easy for blood seekers to manage blood easily and cost effectively. Training staffs of transfusion medicine and using modern technologies and machines increase efficiency and effectiveness in transfusion. Creating connection with blood seekers and blood donors can reduce hassles in managing blood.

\section{Acknowledgements}

We would like to thank all research participants for their support and cooperation. We also thank all hospital authorities who have supported us by providing valuable information.

We would like to express our gratitude to Forhad Uddin Hasan Chowdhury Maruf, Registrar, Department of Medicine, Dhaka Medical College Hospital and Surovi Shabnom Bristi, Intern Doctor, Pabna Medical College Hospital for providing support in data collection.

We would like to express our gratitude to Md. Ashraful Islam, Research Assistant, Access to Information (a2i) Programme for his support.

\section{References}

Akhter, S., Anwar, I., Akter, R., Kumkum, F. A., Nisha, M. K., Ashraf, F., \& Rahman, A. (2016). Barriers to Timely and Safe Blood Transfusion for PPH Patients: Evidence from a Qualitative Study in Dhaka, Bangladesh. PLOS ONE, 11(12), e0167399. https://doi.org/10.1371/journal.pone.0167399

Alam, M., \& Masalmeh, B. E. D. (2004). Knowledge, attitudes and practices regarding blood donation among the Saudi population. Saudi Medical Journal, 25(3), 318-321. Retrieved from http://www.ncbi.nlm.nih.gov/pubmed/15048169

Asia Internet Usage Stats Facebook and 2018 Population Statistics. (n.d.). Retrieved September 4, 2018, from https://www.internetworldstats.com/stats3.htm

Bangladesh Population 2018 (Demographics, Maps, Graphs). (n.d.). Retrieved September 4, 2018, from http://worldpopulationreview.com/countries/bangladesh-population/

Blood donation camp-bdnews24.com. (2013). Retrieved January 4, 2018, from https://bdnews24.com/health/2013/06/20/blood-donation-camp

Blood safety and availability. (n.d.). Retrieved September 4, 2018, from http://www.who.int/news-room/fact-sheets/detail/blood-safety-and-availability

Busch, M. P., Kleinman, S. H., \& Nemo, G. J. (2003). Current and Emerging Infectious Risks of Blood Transfusions. JAMA, 289(8), 959. https://doi.org/10.1001/jama.289.8.959

Facebook makes blood donation easier in Bangladesh | Dhaka Tribune. (n.d.). Retrieved September 4, 2018, from https://www.dhakatribune.com/feature/tech/2018/01/22/facebook-makes-blood-donation-easier

Hosain, G. M., Anisuzzaman, M., \& Begum, A. (1997). Knowledge and attitude towards voluntary blood donation among Dhaka University students in Bangladesh. East African Medical Journal, 74(9), 549-553. Retrieved from http://www.ncbi.nlm.nih.gov/pubmed/9487428

Internet Subscribers in Bangladesh July, 2018.|BTRC. (n.d.). Retrieved September 4, 2018, from http://www.btrc.gov.bd/content/internet-subscribers-bangladesh-july-2018 
Islam, M. B. (2009). Blood transfusion services in Bangladesh. Asian Journal of Transfusion Science, 3(2), 108-110. https://doi.org/10.4103/0973-6247.53880

Klein, H. G., Spahn, D. R., \& Carson, J. L. (2007). Red blood cell transfusion in clinical practice. The Lancet, 370(9585), 415-426. https://doi.org/10.1016/S0140-6736(07)61197-0

Lownik, E., Riley, E., Konstenius, T., Riley, W., \& McCullough, J. (2012). Knowledge, attitudes and practices surveys of blood donation in developing countries. Vox Sanguinis, 103(1), 64-74. https://doi.org/10.1111/J.1423-0410.2012.01600.X

Regional Status Report on Blood Safety and Availability. (2016). Retrieved from http://apps.who.int/iris/bitstream/handle/10665/258923/EMROPub_2017_EN_18907.pdf?sequence=1\&isAl lowed $=\mathrm{y}$

Salaudeen, A., Musa, O., Awoyemi, A., Bolarinwa, A., Adegboye, A., \& Samuel, S. (2011). Community survey on blood donation practices in a northern state of Nigeria. Journal of Preventive Medicine and Hygiene, 52(1). https://doi.org/10.15167/2421-4248/jpmh2011.52.1.243

Sun, T., Lu, S. F., \& Jin, G. Z. (2016). Solving shortage in a priceless market: Insights from blood donation. Journal of Health Economics, 48, 149-165. https://doi.org/10.1016/J.JHEALECO.2016.05.001

Waheed, U., Zaheer, A. M., \& Knowledge, H. A. (2015). Attitude and Practices towards Blood Donation in Pakistan: A Nationwide Survey. Hematology \& Transfusion International Journal, 2015(5), 18. https://doi.org/10.15406/htij.2015.01.00018

WHO | Why should I donate blood? (2018). WHO. Retrieved from http:/www.who.int/features/qa/61/en/

Williamson, L. M., \& Devine, D. V. (2013). Challenges in the management of the blood supply. The Lancet, 381(9880), 1866-1875. https://doi.org/10.1016/S0140-6736(13)60631-5

World Health Organization, World Blood Donor Day 2018: An action of solidarity. (2018). SEARO. Retrieved from http:/www.searo.who.int/bangladesh/wbdd2018/en/

Zaller, N., Nelson, K. E., Ness, P., Wen, G., Bai, X., \& Shan, H. (2005). Knowledge, attitude and practice survey regarding blood donation in a Northwestern Chinese city. Transfusion Medicine, 15(4), 277-286. https://doi.org/10.1111/j.0958-7578.2005.00589.x

\section{Copyrights}

Copyright for this article is retained by the author(s), with first publication rights granted to the journal.

This is an open-access article distributed under the terms and conditions of the Creative Commons Attribution license (http://creativecommons.org/licenses/by/4.0/). 